\title{
The Affection of Implementing Environmental Policy Towards Beijing-Tianjin-Hebei Region
}

\section{Li Zhe}

Business School of Tianjin University of Finances and Economics, Tianjin, P. R. China

\author{
Email address: \\ 15221781892@163.com
}

To cite this article:

Li Zhe. The Affection of Implementing Environmental Policy Towards Beijing-Tianjin-Hebei Region. International Journal of Environmental Protection and Policy. Vol. 5, No. 3, 2017, pp. 43-47. doi: 10.11648/j.ijepp.20170503.13

Received: April 14, 2017; Accepted: May 8, 2017; Published: May 10, 2017

\begin{abstract}
This paper makes use of the revision of "Law on the Prevention and Control of Water Pollution" as a natural phenomenon, under the method of Difference-in-Differences to observe the effect of this policy on the reduction of industrial wastewater in Beijing-Tianjin-Hebei region. The research result shows that the implementation of the policy has certain promoting effect to reduce discharge of industrial wastewater. Administrative regulation plays an important role in environmental protection.
\end{abstract}

Keywords: Difference-in-Differences, Environmental Regulation, Environmental Protection

\section{Introduction}

As the lifeblood of all things on the earth, water moistens everything, nurtures lives while creates civilizations. However, China has been in the water shortage situation for years. According to the United Nations 2008 data, China has $21 \%$ of the world's population while only holds $6 \%$ of the total water resources. The per capita water resource is only about $1 / 4$ of the world average level that makes China as one of the poorest countries of water resources in the world. There are 658 cities in China, over $2 / 3$ of which are lack of water.

As one of the five major city agglomerations in our country, the comprehensive economic strength of the area of Beijing, Tianjin and Hebei is in the forefront of the country. It plays an extremely important role in the social and economic development. In recent years, with the rapid development of economy and the acceleration of the process of urbanization, the problem of industrial water use has been widely concerned. Surveys show that the current Beijing, Tianjin and water resources per capita is only 286 cubic meters, which is far below the internationally recognized per capita of 500 cubic meters that stands for extreme water shortage standards. Because of the over exploitation formed of the country's largest groundwater funnel area. The fracture surface proportion of $\mathrm{V}$ class (functionless water) surface water is more than $30 \%$, and the polluted groundwater accounts for about $1 / 3$. Plain rivers dry up; wetlands shrinking; function decline. Particularly the Haihe River was nourished side. However, the survey in 2013 found that some of its major tributaries are heavily polluted, and class III pollution water is over $60 \%$. In recent years, the water pollution problem in Beijing, Tianjin and Hebei has been widely concerned.

As Beijing Tianjin Hebei collaborative development has become a national strategy, aim at the environmental problems of Beijing Tianjin Hebei frequent, it is critical for develop the three-party cooperation, strengthen the three-party cooperation, accelerate and promote the effect of environmental pollution control [1]. The study of the industrial development of Beijing, Tianjin and Hebei has both practical and theoretical value, which means that the industries can interact with each other [2]. Beijing, Tianjin and Hebei region as one of the most serious water pollution regions in China, will be the focused by environmental protection departments in the next 5 years [3]. Meanwhile, one of the Beijing Tianjin Hebei region is one of the most serious ecological overload and environmental regions, based on the diversity of relevant parties of ecological governance and the break of regional environmental problems, the integration of the ecological environment in the construction of Beijing Tianjin Hebei collaborative development as an opportunity under the regional multi subject cooperative governance and regional inter-governmental collaborative governance [4]. Strengthening the regional ecological environment governance is an important guarantee 
for promoting the coordinated development of Beijing Tianjin Hebei, however, but the differences between the three in the environmental legislation or conflict may restrict the collaborative governance on regional ecological environment [5].

This paper analyzes in detail the impact of environmental regulations on reduction of wastewater in Beijing, Tianjin and Hebei regions. It found that there is a negative correlation between them---environmental regulations really inhibit of the reduction of wastewater. In the research process, two problems have been solved. (1) The measurement of environmental regulations subjects to possibly errors, causing the results are not accurate enough. The paper introduces the revision of "Law on the Prevention and Control of Water Pollution" as a natural phenomenon to avoid this problem. (2) This paper attributes all the reduction of wastewater to environmental regulations may be controversial, so the design of model adds control variables to make regression results reasonable. Finally, this study can be used to evaluate the legal effect.

\section{Literature Review}

Facing the worsening environment, the means of administrative regulation is particularly important. Regard to the researches in China, Wang Jie pointed out that it is of great significance to establish a reasonable level of environmental regulation and differentiated environmental regulation policies for pollution control and the improvement of total factor productivity. The environmental regulation has no facilitating effect on pollution emission control, and there is a significant positive correlation between the expenditure of local government and environmental pollution, which reflects the current lack of local governments to control environmental pollution enthusiasm and forward-looking and the country is facing more and more environmental pollution governance dilemma [6]. In terms of policy, the differences between regions should also be taken into account, as pointed by Jin Xiangrong, regional differences in environmental policies often lead to regional differences in actual production costs for high polluting industries, furthermore, it has an important influence on regional industrial transfer and structure change. Otherwise, scale effect is the main reason for the increase of industrial wastewater discharge and technical effect is the key factor of industrial wastewater emission reduction, the structural effects are mostly negative values with small absolute values [7].

Li Shu uses the revision of China's "Atmospheric Pollution Prevention Law" (APPCL2000) in 2000 as a natural experiment, with the method of double difference to assess the influence of APPCL2000 revision on TFP growth in China's industrial sector. Tang Yun uses panel data regression analysis to test the effect of the establishment of acid rain pollution and sulfur dioxide pollution control area policy on the SO2 discharge and economic growth. It can be seen that the implementation of laws and policies has certain influence on environmental protection.

\section{Legislation Background}

Since the reform and opening to the outside world, the prevention of water pollution has been the focus of our country. Further to this, our country has promulgated the corresponding laws, mainly including: "Regulations of the People's Republic of China on the Management of River Courses" passed on the seventh executive meeting of the State Council in 1988, and promulgated by the State Council Order No. 3 on June 10, 1988, and come into force as of the date of promulgation. The implementation of this regulation not only to adapt to the needs of economic and social development, but also manage and protect of the river legally, and ensuring the safety of flood control, water supply safety and ecological safety of water, finally give full play to the comprehensive benefit of rivers and lakes. On August 29, 2002, the revision of "Water Law of the People's Republic of China" was passed on the twenty-ninth session of the Standing Committee of the Ninth National People's Congress, and come into force since October 1, 2002, it provides a good guarantee for the rational utilization, development, protection and conservation of water resources, while can achieve the sustainable use of water resources, to meet the needs of national economic and social development. In order to prevent and control soil and water loss, protect and reasonably utilize water and soil resources, reduce water, drought and sandstorm disasters, improve ecological environment, and ensure the sustainable development of economy and society, "People Republic of soil and water conservation Law" was released and implemented by Standing Committee of the National People's Congress on June 26, 1991, and revised on December 25, 2010. In order to prevent and control water pollution, protect and improve the environment, ensure the safety of drinking water, and promote the comprehensive, coordinated and sustainable development of economy and society, on February 28, 2008, "Water Pollution Prevention and Control Law of the People's Republic of China" was passed on the tenth meeting of the Standing Committee of the People's Republic of China National People's Congress the thirty-second session, and implemented since June 1, 2008.

This paper will base on the revision of "Law on the Prevention and Control of Water Pollution", observe the impact of the policy on industrial wastewater discharge in Beijing Tianjin Hebei region before and after the implementation. And divide the cities in Beijing, Tianjin and Hebei region into two categories: 1. Economically developed and underdeveloped cities; 2 . Central and non central cities.

\section{Model Design and Variable Selection}

\subsection{Model Design}

Double difference method is used in this paper. As defined by double difference method, considered one event as an random natural event impact, compare the treatment group and the control group before and after the impact, treatment effect would be "the changes of treatment group before and after impact" deduct "The change of the treatment group in the 
absence of impact", i.e.:

$$
\beta=E\left(y_{A}^{1}-y_{B}^{1} \mid D=1\right)-E\left(y_{A}^{0}-y_{B}^{0} \mid D=1\right)
$$

in which, $D=1$ is treatment group, $\left(y_{A}^{1}-y_{B}^{1}\right)$ is the change before and after impact, $\left(y_{A}^{0}-y_{B}^{0}\right)$ is the self change in the absence of impact. But we can see treatment effect is a kind of counterfactual effect, a) for before impact, $y_{A}^{0}=y_{B}^{0}$; b) for after impact, only $y_{A}^{1}$ could be observed without $y_{A}^{0}$. So control group should be introduced, i.e.

$$
\beta=E\left(y_{A}^{1}-y_{B}^{1} \mid D=1\right)-E\left(y_{A}^{0}-y_{B}^{0} \mid D=0\right) \quad, \quad D=0 \quad \text { is }
$$
control group.

This paper considered the revision of "Law on the Prevention and Control of Water Pollution" as a random natural impact, divided in to treatment group and control group base on regional economic strength difference between Beijing, Tianjin and Hebei region, i.e. $H=1$ developed area, $H=0$ undeveloped area. The effect to developed area could be described as $\beta_{d}=E\left(w_{a}^{1}-w_{b}^{1} \mid H=1\right)-E\left(w_{a}^{0}-w_{b}^{0} \mid H=1\right)$, $\left(w_{a}^{1}-w_{b}^{1}\right)$ is the changes in discharge in developed areas before and after the implementation; regarded to underdeveloped area, it could be described as $\beta_{u}=E\left(w_{a}^{1}-w_{b}^{1} \mid H=0\right)-E\left(w_{a}^{0}-w_{b}^{0} \mid H=0\right)$. The "net effect" to developed area could be described as $\beta_{d}=E\left(w_{a}^{1}-w_{b}^{1} \mid H=1\right)-E\left(w_{a}^{0}-w_{b}^{0} \mid H=0\right)$. "net effect" is the change of reduction effect in developed and underdeveloped areas.

\subsection{Variable Selection}

Base on above discussion, set the model as:

$$
\ln w_{i t}=\alpha_{0}+\alpha_{1} \text { develop }_{i t} \times \text { time }_{i t}+\sum_{j=1}^{3} \beta_{j} \ln X_{i t j}+\varepsilon_{i t}+\delta_{i t}+\mu_{i t}
$$

In which $\mathrm{w}$ is unit discharge of industrial waste water, develop is dummy variable of urban economic development, develop $=1$ is developed city, develop $=0$ underdeveloped city, time is dummy variable of time. As "Law on the Prevention and Control of Water Pollution" was revised in 2008, time=1 is at and after 2009 , time $=0$ is before 2009. $\mathrm{X}$ is control variable, introduce education, tech and outward. education is expenditure on education in total fiscal expenditure of city $t$ in year $i$, tech is science and technology expenditure in total fiscal expenditure of city $t$ in year $i$, outward is the economic export-oriented degree of city $t$ in year $i$, reflected by the proportion of foreign investment. According to research, the effect of environmental regulation should be more obvious in developed areas, so $\alpha_{1}<0$; according to the relevant theoretical analysis, with the improvement of education level, the input of science and technology expenditure and the increase of export-oriented economy, inhibition of wastewater discharge would be promoted, so $\beta_{j}<0$.

Otherwise, taking into account the effect of environmental regulation on different geographical location of the city will have different effects, reset the model:

$$
\ln w_{i t}=\gamma_{0}+\gamma_{1} \text { center }_{i t} \times \text { time }_{i t}+\sum_{j=1}^{3} \phi_{j} \ln Z_{i t j}+\eta_{i t}+\kappa_{i t}+\varsigma_{i t}
$$

In which, center is dummy variable of city location, center $=1$ is central city, cent $=0$ is non central city. $Z$ is control variable, introduce student, traffic and green. Student is the number of college students per million of city $t$ in year $i$, traffic is personnel mobility of city $t$ in year $i$, reflected by railway passenger volume, green is greening rate. The environmental regulation should have a greater impact on the central city, so $\gamma_{1}<0$; the increase in the number of college students, the mobility of personnel and the expansion of the green rate should help to reduce waste water, so $\phi_{j}<0$.

\section{Data and Result}

\subsection{Data Selection}

All the data in this paper are taken from Beijing Tianjin Hebei region in "China urban statistical yearbook" 2014-2015, including total industrial wastewater discharge and industrial output value of Beijing, Tianjin and other 11 prefecture level cities in Hebei (see Fig. 1). It is easy to find after 2008, the total amount of industrial wastewater in Beijing, Tianjin and Hebei showed a downward trend, while the gross industrial output value of the region showed a clear upward trend.

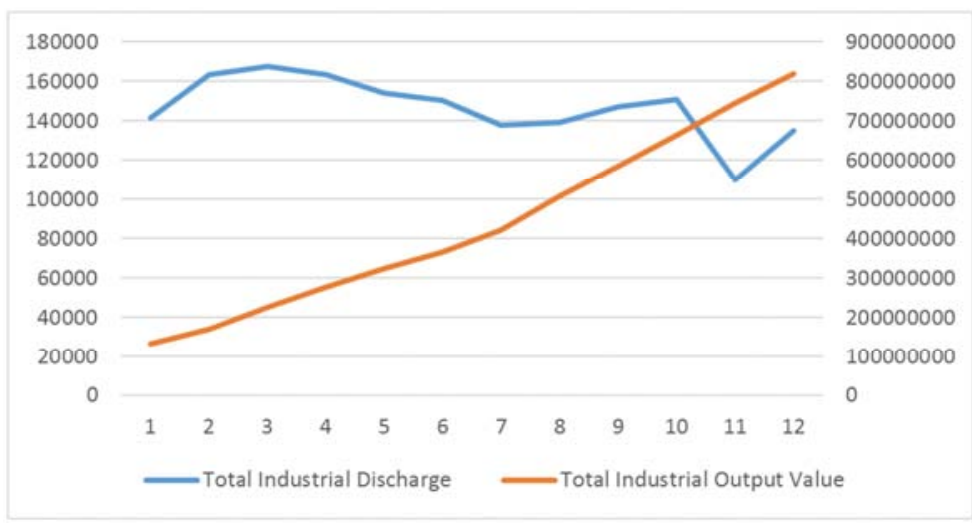

Figure 1. Total industrial wastewater discharge. 


\subsection{Result Analysis}

First, using stata 14 to estimate the equation (1), regression results as shown in Table 1 .

Table 1. The effect of "Law on the Prevention and Control of Water Pollution" Towards Developed Cities.

\begin{tabular}{lllll}
\hline & Result (1) & Result (2) & Result (3) & Result (4) \\
\hline \multirow{2}{*}{ constant term } & $-9.2336^{* * *}$ & $-8.5669^{* * *}$ & $-8.6512^{* * *}$ & $-8.5413^{* * *}$ \\
& $(-11.00)$ & $(-9.71)$ & $(-11.93)$ & $(-30.48)$ \\
develop $\times$ time & $-0.5646^{* * *}$ & $-0.6809^{* * *}$ & $-0.0715^{* * *}$ & $-0.6755^{* * *}$ \\
& $(-3.39)$ & $(-3.99)$ & $(-8.74)$ & $(-10.47)$ \\
ln education & $1.4165^{* * *}$ & $2.0689^{* * *}$ & $0.6338^{*}$ & $0.9455^{* * *}$ \\
& $(4.04)$ & $(5.13)$ & $(1.74)$ & $(9.00)$ \\
ln tech & $-0.6378^{* * *}$ & $-0.6518^{* * *}$ & $-0.3643^{* * *}$ & $-0.3556^{* * *}$ \\
& $(-10.35)$ & $(-10.26)$ & $(--5.38)$ & $(-12.77)$ \\
$\ln$ outward & $-0.1614^{* *}$ & $-0.2175^{* *}$ & $-0.1297^{*}$ & $-0.1556^{* * *}$ \\
Wald & $(-2.08)$ & $(-2.57)$ & $(-1.76)$ & $(-7.13)$ \\
$N$ & 229.57 & 202.96 & 326.08 & 640.92 \\
\hline
\end{tabular}

Note: the $\mathrm{z}$ statistics is in brackets, in which ${ }^{* * *},{ }^{* *},{ }^{*}$ stands for significance level at $1 \%, 5 \%$ and $10 \%$ individually.

Result (1) and (2) are results of fixed effects and random effects in OLS estimation, after Hausman test results were 10.48 , so under the significance level at $10 \%$ select fixed effect, every $1 \%$ increase in developed cities, industrial wastewater discharge will be reduced by about $0.56 \%$. Put actual per capita GDP into equation (1), i.e. develop is actual per capita GDP, estimate result under OLS as result (3), every $1 \%$ increase in developed cities, industrial wastewater discharge will be reduced by about $0.07 \%$. Base on above results, process different variance between groups, autocorrelation in the group and same period related inspection, result shown average $P$ value is 0 , so only GLS could be selected, regression result as result (5), every $1 \%$ increase in developed cities, industrial wastewater discharge will be reduced by about $0.68 \%$.

Then using stata14 to estimate the equation (2), regression results as shown in Table 2

Table 2. The effect of "Law on the Prevention and Control of Water Pollution" Towards Central Cities.

\begin{tabular}{llll}
\hline & Result (1) & Result (2) & Result (3) \\
\hline \multirow{2}{*}{ constant term } & $3.9971^{* * *}$ & $-2.9730^{* * *}$ & $-2.7903^{* * *}$ \\
& $(3.18)$ & $(-10.09)$ & $(-3.54)$ \\
center $\times$ time & $-0.4598^{* * *}$ & $-0.2635^{* * *}$ & $-0.1723^{*}$ \\
& $(-2.61)$ & $(-5.90)$ & $(-1.94)$ \\
In student & $-1.1415^{* * *}$ & $-0.2373^{* * *}$ & $-0.5272^{* *}$ \\
& $(-5.83)$ & $(-6.84)$ & $(-4.05)$ \\
ln traffic & $-0.5771^{* * *}$ & $-0.2230^{* * *}$ & $-0.3939^{* * *}$ \\
& $(-3.10)$ & $(-8.90)$ & $(-6.20)$ \\
ln green & -0.5874 & $-0.5131^{* * *}$ & $-0.1624^{*}$ \\
Wald & $(-1.41)$ & $(-6.49)$ & $(-3.54)$ \\
$N$ & 158.08 & 371.04 & 127.99 \\
\hline
\end{tabular}

Note: the $\mathrm{z}$ statistics is in brackets, in which ${ }^{* * *},{ }^{* *},{ }^{*}$ stands for significance level at $1 \%, 5 \%$ and $10 \%$ individually.

Hausman test results for model (2) were 19.89, fixed model
(2) should use fixed effect, estimated result as result (1), i.e. when the central city policy changes before and after the implementation at $1 \%$, industrial wastewater discharge will be reduced by about $0.46 \%$. Result (2) is GLS result, when the central city policy changes before and after the implementation at $1 \%$, industrial wastewater discharge will be reduced by about $0.26 \%$. Considering the difference between cities, three cities are selected to match central cities. As shown in result (3), when the central city policy changes before and after the implementation at $1 \%$, industrial wastewater discharge will be reduced by about $0.17 \%$.

\section{Conclusion}

As a fast developing country, China is facing both economic growth and resource protection needs. There are still many deficiencies, especially in the utilization of water resources and water pollution. It is important to further enhance national awareness and strengthen the implementation of policy. This paper makes use of the revision of "Law on the Prevention and Control of Water Pollution" as a natural phenomenon, under the method of Difference-in-Differences to compare the effects before and after the implementation of policy, find the amount of industrial waste water discharged has been changed significantly before and after the implementation of the policy in developed cities. Meanwhile, the implementation of the law has a significant impact on the central city.

While in the research, there are differences in implementation of policy in each city, which may cause the research not comprehensive. All in all, the implementation of the policy does promoting the environmental protection. So to strengthen the environmental construction, perfect the law of our country is the only way.

\section{References}

[1] Husong Cui, Mingna Yang. Research on Effectiveness of Environment Pollution Control of Beijing-Tianjin-Hebei Based on SCP Mode. Ecological Economy [J], 2015.12.

[2] Hu Sun, Biao Qiao. Study on Problems in Beijing, Tianjin and Hebei Coordinate Industrial Development and Recommendations. China Soft Science [J], 2015.7.

[3] Wenjuan Duan. Beijing-Tianjin-Hebei: Another serious areas of water pollution. Journal of Earth [J], 2016.2.

[4] Zhe Wang, Lingyi Zhou. The Collaboration of Regional Ecological Environment Governance of Beijing-Tianjin-Hebei-From the Institutional Perspective. Research on Economics and Management [J], 2015.7.

[5] Qingyu Meng. On the Cooperative Legislation Safeguard Mechanism of the Jing-Jin-Ji Region's Environmental Governance. Journal of Political Science and Law [J], 2016.2.

[6] Zhiying Ji, Jie Mao, Xiaofeng Lai. Study on the Effect of FDI on Environmental Pollution in China: An Empirical Test with the Panel Data Model. World Economy Studies [J], 2015.3. 
[7] Changjia Li, Chengzhong Pan, Hongjun Lei, Pei Tian. Decomposition Analysis on China's Industrial Wastewater Discharges in 1992-2008. Research of Environmental Sciences, 2013.5.

[8] Jie Wang, Bin Liu. Environmental Regulation and Enterprises' TFP-An Empirical Analysis Based on China's Industrial Enterprises Data. China Industrial Economics [J], 2014.3.

[9] Shu Li, Gang Chen. Environmental Regulation and the Growth of Productivity in China-Evidence from the Revision of Air Pollution Prevention and Control Law in 2000. Economic Research Journal [J], 2013.1.
[10] Xiangrong Jin, Lili Tan. Differences in Environmental Policies and Transfer of Regional Industry: A Perspective of New Economic Geography (NEG). Journal of Zhejiang University (Humanities and Social Sciences) [J], 2012.9.

[11] Allen F., J. Qian, M. J. Qian. Law, Finance, and Economic Growth in China. Journal of Financial Economics [J], 2005.77(1).

[12] D. Z. Zeng. New Economic Geography with Heterogeneous Preferences: An Explanation of Segregation. Journal of Urban Economic [J], 2008. 63(1). 